\title{
A mente brasileira em estado de possessão: contribuição de um estudo de caso para a psicologia da religião e saúde mental no Brasil
}

The Brazilian mind possessed: towards a psychology

of religion and mental health in Brazil

\section{Romara Delmonte, Miguel Farias*}

Coventry University, Coventry, England

\section{Resumo}

Apesar da prática de possessão em contexto religioso ser relativamente comum e transcultural, como por exemplo nas religiões afro-brasileiras, nas religiões espíritas, nas igrejas cristãs neopentecostais e carismáticas, há relativamente pouca pesquisa sobre a saúde mental e os correlatos psicológicos dos indivíduos que vivenciam estes estados de possessão. Essas experiências podem ser facilmente confundidas com sintomas dissociativos ou psicóticos, constituindo-se muitas vezes em um desafio para o diagnóstico clínico. Nesse artigo, utilizamos o estudo de caso de uma líder religiosa de

\footnotetext{
* RD: Graduada em Psicologia, e-mail: romaradelmonte@yahoo.com.br MF: Titulação, e-mail: miguel.farias@coventry.ac.uk
} 
Umbanda de modo a realizar uma pesquisa fenomenológica e clínica, que tente diferenciar a experiência de possessão saudável da patologia de Transtorno Dissociativo de Identidade, consoante os critérios do DSM 5. Na nossa conclusão, questionamos a precisão do diagnóstico de Transtorno Dissociativo de Identidade, particularmente na sua falta de atenção ao contexto social. Terminamos com um apelo aos psicólogos brasileiros para fortalecerem a pesquisa em uma área tão relevante para a sociedade brasileira, ao invés de apenas apostarem no estudo de temáticas espirituais que vêm do estrangeiro (como por exemplo, a mindfulness, de raiz budista).

Palavras-chaves: Fenômeno de possessão. Transtorno Dissociativo de Identidade. DSM 5. Experiência religiosa. Umbanda.

\section{Abstract}

Although religious possession practices are relatively common events across cultures, such as in Afro-Brazilian, Spiritist, and Neo-Pentecostal groups, there is an overall lack of research about the mental health and psychological correlates of individuals who experience these states of possession. These experiences can be easily confounded with dissociative or psychotic symptoms, and represent a challenge for an accurate clinical diagnosis. In this article, we use the case study of an Afro-Brazilian religious leader and the DSM 5 criteria of Dissociative Identity Disorder, in order to attempt differentiating healthy possession experiences from pathological ones. We question the accuracy of the DSM 5 diagnostic criteria of Dissociative Identity Disorder, particularly in its lack of attention to the social context. We end the article by suggesting that Brazilian psychologists of religion should consider this topic a research priority, instead of focusing most of their energies on the study of spiritual themes that aren't native to Brazilian culture (such as Buddhist-based mindfulness).

Keywords: Possession. Dissociative Identity Disorder. DSM 5. Religious Experience. Umbanda. 


\section{Introdução}

Os estados de possessão são comuns em diversas culturas tribais, rurais e urbanas. Bourguignon (1973) relatou que a estimulação ritual de estados alterados de consciência, particularmente aqueles associados com a possessão, estão presentes em mais de 450 sociedades. Dizemos que a crença na possessão existe quando uma determinada pessoa se encontra em um profundo estado alterado de consciência, interpretado como sendo causado pela presença de uma entidade espiritual ou de um poder sobrenatural, e essa alteração não provém de sua própria personalidade (COHEN, 2007).

Estados de possessão também estão classificados como uma categoria patológica dentro dos quadros de Transtornos Dissociativos do Manual Diagnóstico e Estatístico (DSM 5; American Psychiatry Associationk, 2013), sendo caracterizados por perturbação e/ou descontinuidade da integração normal de consciência, memória, identidade, emoção, percepção, representação corporal, controle motor e comportamento. O manual considera que existe um Transtorno Dissociativo de Identidade quando se dá a presença de dois ou mais critérios, que incluam o critério $C$, respeitante ao sofrimento clinicamente significativo e prejuízo no funcionamento social, profissional ou outras áreas importantes da vida do indivíduo.

O Manual esclarece que a maioria dos estados de possessão ocorrem como parte de práticas aceitas culturais/espirituais e não inclui sofrimento clínico. Contudo, apesar dessa distinção genérica entre a possessão enquanto fenômeno cultural não patológico e a possessão enquanto patologia, o Manual, ainda assim, não oferece detalhes que possibilitem ao clínico fazer um diagnóstico acurado, e menos ainda, recursos para um tratamento adequado. É também pertinente o comentário dos Grof, quando defendem que é importante evitar: "por um lado 'patologizar' os estados místicos ou, por outro lado, de espiritualizar os estados psicóticos e glorificar a patologia" (GROF; GROF, 2001).

Essa questão é particularmente pertinente num país como o Brasil, dada a riqueza religiosa e proliferação de grupos (espíritas, afro-brasileiros e pentecostais) onde se apresentam rituais frequentes ligadas à 
possessão. Alguns autores notam a falta de estudos sistemáticos nesta área (ALMEIDA, ALVARADO, ZANGARI, 2007, p. 289). Nesse artigo, temos como primeiro objetivo contribuir para a literatura de possessão religiosa e saúde mental, considerando um estudo de caso de uma líder religiosa de Umbanda. Caracterizada por rituais envolvendo música e dança, oriundo de religião africanas (BASTIDE, 1995), a Umbanda inclui uma ampla gama de entidades espirituais (tanto espíritos da natureza como supostamente seres humanos falecidos) que prestam aconselhamento moral, prático e cura. Como Segundo Objetivo, utilizaremos esse caso para analisar a diferenciação entre possessão patológica e saudável. Consideramos que se por um lado há manifestações de possessão saudáveis, também haverá as não saudáveis - dentro e fora de contextos religiosos.

\section{Método}

Este estudo de caso se foca sobre Dona Sara Jerónimo (pseudônimo), uma líder religiosa de Umbanda de 55 anos. O primeiro autor recolheu dados ao longo de cinco entrevistas semiestruturadas (2 horas cada), com foco no desenvolvimento da vida, na experiência de possessão e outras experiências incomuns desde a infância até o presente. As entrevistas foram transcritas e sujeitas a uma análise de conteúdo pelos autores, particularmente tendo em conta as experiências de possessão de Dona Sara, incluindo as sensações associadas, emoções e conexões sociais e familiares, de modo a examiná-las em relação aos critérios do DSM-5 para Transtorno Dissociativo de Identidade.

\section{Descrição do caso}

Dona Sara lidera grupos de Umbanda, fornecendo aconselhamento e cura para mais de 150 pessoas regularmente. Ela relatou que dorme em média 5 horas por noite, ou menos quando está em estado de possessão. $\mathrm{Na}$ época em que foi entrevistada, ela nunca havia ido a um psiquiatra ou 
psicólogo clínico. Também relatou não tomar drogas ou álcool, embora quando possuída muitas vezes beba vinho ou cachaça, ainda que enfatize não sentir efeitos após sair do estado de possessão.

\section{Primeira fase: experiências da infância aos 27 anos}

Dona Sara relatou que desde a idade de sete anos até por volta dos treze, aconteceram fatos incomuns que marcaram sua infância: "Desde muito nova tive experiências fora do comum, começou a vir no meu pensamento que ia acontecer algo com alguém, eu falava e acabava acontecendo por volta de três dias, quatro dias depois". Segundo ela, sua família começou por protegê-la, porque: "parecia que o que eu falava acontecia e ficava um mal-estar depois". Esses pensamentos se relacionavam com várias previsões, como falecimento ou doenças em sua família ou comunidade próxima: "Eu falava com alguém da minha casa e aquilo infelizmente acontecia realmente e muito rapidamente". Sua família era católica praticante e Dona Sara relatou que nas missas aproveitava para rezar bastante, pois se sentia muito mal pensando que as desgraças eram culpa dela, que havia sido ela que havia provocado ("eu rezava muito na igreja pois eu achava que eu rezando que aquilo das mensagens que eu recebia não aconteceria mais").

Quando pedimos para descrever essas mensagens, ela explicou que: "A mensagem chegava pronta na minha mente como um pensamento que não criei, era forte, como uma mensagem mesmo e aquilo não saia da minha mente". Dona Sara relatou que ingressou num colégio religioso, mas que os fenômenos continuaram a acontecer: "Eu pedia a Deus que não deixasse mais aquilo acontecer, então rezava muito e essas experiências sobrenaturais paravam por uns dias. Mas sempre voltavam."

Dona Sara salientou três fatos que marcaram de modo particular sua infância e pré-adolescência. O primeiro foi uma dessas "premonições": "Fui numa venda na esquina da minha casa. Ao ver o dono, que sempre me atendia, senti algo forte. Quando me deparei com ele, falei: ai, acho que o senhor vai passar mal e até pode morrer." Segundo Dona Sara todos escutaram na venda e houve uma reunião na família para saber como procederiam com ela: "A família queria me esconder porque todos ouviram e ficou um clima péssimo no bairro". Segundo ela, o homem viria a morrer 
dali a três dias: "Foi uma repercussão muito grande na cidade, o clima foi horrível, todos começaram a falar que tinha algo de feiticeira comigo".

Um segundo acontecimento que a marcou, envolveu um momento de oração em que vestiu "uma roupa branca e um lençol branco na cama", se deitou e não voltou a se levantar durante bastante tempo, entrando "num estado fora do comum, de uma paz, tranquilidade e sensações que nunca havia sentido". Ela considera ser essa a sua primeira experiência de possessão ou transe profundo.

O terceiro fato marcante ocorreu quando o irmão, com o intuito de a curar das suas "premonições" a levou a um grupo de Candomblé. Dona Sara nos relatou que quando lá chegou com seu irmão, "tive uma manifestação forte e imediata e no meio de muita gente dançando e cantando, vivi um transe". Contudo, não se sentiu bem com essa experiência. Ficou assustada e angustiada com o ocorrido, sem entender o que se passara consigo. Ademais, aquela forma de religião não lhe era familiar.

\section{Segunda fase: dos 27 anos em diante}

Com vinte e seis anos, as mensagens "premonitórias" começaram a ocorrer novamente com muita frequência e intensidade. Resolveu então procurar ajuda. Na sua rua havia um terreiro de Umbanda e se dirigiu para lá para contar o que se passava com ela desde a infância e tentar obter explicações. Dona Sara relata que desde o primeiro contato com a mãe de santo desse terreiro, ela sentiu que encontrara finalmente alguém que entendia todos os fenômenos incomuns por ela vivenciados até então: "Fui me encantando por aquele espaço. Aquela mãe de santo muito segura, tranquila, que estava entendendo a minha história, entendendo o que acontecia comigo. Era como se fosse um curativo. Eu me sentia num consultório médico e que eu podia falar a mesma língua. Ela me disse que eu era um aparelho mediúnico e que deveria buscar entender para ajudar algumas pessoas e ajudar a mim, que isso eram coisas que também existiam no mundo".

Na primeira vez que Dona Sara, a convite mãe de santo, foi assistir ao ritual disse sentir receio, até que foi levada para o meio da roda. Nesse momento, ela contou que sentiu um zumbido muito forte no ouvido, uma 
espécie de "sino, só que contínuo, muito forte mesmo. Quando voltei em mim, vi que havia acontecido uma manifestação, eu estava suada e que tinha acontecido algo que não era eu." Acrescenta ainda: "Me senti muito anestesiada, com pouquíssima percepção do ambiente durante a manifestação". Desde esse dia, ela começou a participar ativamente das sessões de Umbanda e os transes começaram a ocorrer com frequência, mas de forma controlada, como parte do ritual.

Indagada sobre se lembrava-se do que acontecia quando em estado de possessão, ela explicou que: "Foi tudo um pouco gradual", no início se sentia como se estivesse "numa cortina de fumaça e "via o grupo em volta e escutava tudo que acontecia como se estivesse tudo acontecendo com muita distância”. Ela explicou que no dia seguinte ao ritual, não mais conseguia se recordar quase nada do ocorrido. Relatou também não ter controle sobre algumas partes do seu corpo, embora não fosse tomada de forma involuntária: "me aproximava do altar e a entidade se manifestava". Nos três primeiros anos de experiência religiosa de possessão, a sua consciência da possessão se foi tornando mais e mais apagada, passando de "semiconsciente" para "totalmente inconsciente". Especificou que, no início, não deixava de sentir o corpo como um todo. Essa perda de sensação foi gradual: começou por deixar de sentir uma perna ou um braço; outras vezes não sentia ambas as pernas. Nesses casos, após incorporar não tinha domínio sobre esses membros, embora escutasse de longe o que era dito.

Hoje em dia, afirmou não ter absolutamente nenhuma consciência ou memória do estado de possessão. E ilustra com um caso, para ela inexplicável, em que estando acamada, por ter sido recém operada devido a um tombo em que havia fissurado duas vértebras, sem conseguir "se mexer nem mesmo centímetros na cama", conduziu uma reunião de Umbanda na cama para cerca de sessenta pessoas. Ela narrou que conduziu todos os procedimentos do ritual dando comandos orais até que, sem o esperar, entrou em estado de possessão, dançando forró e andando pelo salão. Na hora de sair do estado de possessão, a "entidade que incorporava" orientou alguns membros do ritual que fizessem uma parede humana em volta para que Dona Sara, recuperando sua consciência, não caísse; 
segundo ela, a entidade que a possuía explicou aos demais: "a $\mathrm{Baba}^{1}$ não acreditará que estive aqui dançando e trabalhando, fala com ela que as dores vão passar".

Ao descrever seus transes atuais, ela relatou que quando está em frente ao altar se preparando sente confiança e entrega. Começa por sentir sua respiração alterada e depois seu corpo tremulando. "É como uma anestesia geral", Dona Sara explica, relatando perder totalmente a consciência de cada parte do corpo e da mente: "Isso hoje ocorre em segundos, não tem como descrever cada etapa, é tão rápido que não sei precisar. Só vou ver o grupo e as pessoas horas depois, e volto com a sensação de estar amanhecendo, exatamente a sensação que temos ao acordar com a diferença que me sinto extremamente descansada e leve, sem fome, sem vontade ir ao banheiro, como se estives, se num sono rejuvenescedor. Sinto uma paz e uma plenitude indescritível".

Quando questionada sobre se sente mistura ou indefinição de quem seria ela em relação às entidades, respondeu negativamente: "Não. Eu nem me aguentaria com tanto "eus", eu quero ser "eu" mesmo. Eles estão em outro espaço, outro plano. Eu os respeito e eles respeitam meu espaço também".

\section{Diferenciando transtorno dissociativo de identidade da possessão saudável: análise baseada nos critérios do DSM-5}

As experiências de possessão de Dona Sara se dividem em duas fases distintas. A primeira cobre a sua infância e o início da sua idade adulta, sendo caracterizada por pensamentos intrusivos e estados de possessão. Estas experiências eram associadas com um elevado estado de ansiedade, solidão, e conflitos familiares diante do estigma social da ocorrência desses fenômenos - note-se que essas experiências se passavam num contexto social onde não eram aceitáveis - além da falta de controle sobre a possessão. No entanto, ao mesmo tempo, Dona Sara muitas vezes descreve essa experiência de possessão como "agradável" ou "boa". Dona

1 Segundo Dona Sara, nome carinhoso e ritualístico com que algumas entidades se referem às mães de santo. 
Sara relata sofrimento emocional (como descrito no Critério C do DSM 5; ver Tabela 1), tais como a sua falta de controle pessoal sobre intrusões de pensamento e alterações do sentido de si mesmo, ressaltando que tudo isso era agravado pela desaprovação social da família, comunidade e colegas perante os fenômenos que ela vivenciava.

Tabela 1 - Critérios do DSM 5 para Transtorno Dissociativo de Identidade e Diagnóstico em Dois Estágios do Estudo de Caso

(Continua)

\begin{tabular}{|c|c|c|c|}
\hline Critério Diagnóstico & $\begin{array}{c}\text { Antes dos } \\
27 \text { anos }\end{array}$ & $\begin{array}{l}\text { Depois dos } \\
27 \text { anos. }\end{array}$ & Estudo de Caso \\
\hline $\begin{array}{l}\text { A. Ruptura da identidade } \\
\text { caracterizada pela presença de dois } \\
\text { ou mais estados de personalidade } \\
\text { distintos, descrita em algumas } \\
\text { culturas como uma experiência de } \\
\text { possessão. A ruptura de identidade } \\
\text { envolve descontinuidade acentuada } \\
\text { no senso de si mesmo e de domínio } \\
\text { das próprias ações, acompanhada } \\
\text { por alterações no afeto, no } \\
\text { comportamento, na consciência, na } \\
\text { memória, na percepção, na cognição } \\
\text { e/ou no funcionamento sensório- } \\
\text { motor. Esses sinais e sintomas } \\
\text { podem ser observados por outros ou } \\
\text { relatados pelo indivíduo. }\end{array}$ & $\operatorname{sim}$ & $\operatorname{sim}$ & $\begin{array}{l}\text { Durante a infância e na idade } \\
\text { adulta, Dona Sara relatou } \\
\text { episódios de perturbação de } \\
\text { identidade, caracterizada pela } \\
\text { perda de sentidos e consciência } \\
\text { do tempo, bem como sintomas } \\
\text { comportamentais (como agitação } \\
\text { e palpitações cardíacas). }\end{array}$ \\
\hline $\begin{array}{l}\text { B. Lacunas recorrentes na } \\
\text { recordação de eventos cotidianos, } \\
\text { informações pessoais importantes } \\
\text { e/ ou eventos traumáticos que são } \\
\text { incompatíveis com o esquecimento } \\
\text { comum. }\end{array}$ & $\operatorname{sim}$ & $\operatorname{sim}$ & $\begin{array}{l}\text { Dona Sara relata amnésia parcial } \\
\text { ou completa durante os períodos } \\
\text { de possessão. Embora ela relate } \\
\text { ter estado vagamente consciente } \\
\text { durante a primeira experiência } \\
\text { de possessão, está inconsciente } \\
\text { durante a segunda. Na segunda } \\
\text { parte de sua vida, ela compara } \\
\text { sua possessão a um estado de } \\
\text { sono profundo. }\end{array}$ \\
\hline $\begin{array}{l}\text { C. Os sintomas causam sofrimento } \\
\text { clinicamente significativo e prejuízo } \\
\text { no funcionamento social, profissional } \\
\text { ou em outras áreas importantes da } \\
\text { vida do indivíduo. }\end{array}$ & sim & não & $\begin{array}{l}\text { Na infância, ela relata angústia } \\
\text { social e psicológica acentuada } \\
\text { ao lidar com suas experiências } \\
\text { incomuns e estados de } \\
\text { possessão. Este sofrimento deixa } \\
\text { de existir após a Dona Sara se } \\
\text { juntar a um grupo de Umbanda. }\end{array}$ \\
\hline
\end{tabular}




\begin{tabular}{|c|c|c|c|}
\hline & & & (Conclusão) \\
\hline Critério Diagnóstico & $\begin{array}{c}\text { Antes dos } \\
27 \text { anos }\end{array}$ & $\begin{array}{c}\text { Depois dos } \\
27 \text { anos. }\end{array}$ & Estudo de Caso \\
\hline $\begin{array}{l}\text { D. A perturbação não é parte } \\
\text { normal de uma prática religiosa ou } \\
\text { cultural amplamente aceita. Nota: } \\
\text { Em crianças, os sintomas não são } \\
\text { explicados por amigos imaginários } \\
\text { ou outros jogos de fantasia. }\end{array}$ & $\operatorname{sim}$ & não & $\begin{array}{l}\text { Atualmente, os estados de } \\
\text { possessão regulares de Dona } \\
\text { Sara são enquadrados dentro } \\
\text { de um contexto religioso. } \\
\text { Porém, antes dos } 27 \text { anos, seus } \\
\text { sintomas de aflição interpessoal } \\
\text { dentro de sua família e da } \\
\text { comunidade eram graves. } 0 \\
\text { que ela experimentou não fazia } \\
\text { parte de sua cultura e educação } \\
\text { católica tampouco era aceite } \\
\text { pela sua família. }\end{array}$ \\
\hline $\begin{array}{l}\text { E. Os sintomas não são atribuíveis } \\
\text { aos efeitos fisiológicos de uma } \\
\text { substância (p. ex., apagões ou } \\
\text { comportamento caótico durante } \\
\text { intoxicação alcóolica) ou a outra } \\
\text { condição médica (p. ex., convulsões } \\
\text { parciais complexas). }\end{array}$ & $\operatorname{sim}$ & $\operatorname{sim}$ & $\begin{array}{l}\text { Tanto durante a infância e como } \\
\text { na vida adulta, os estados de } \\
\text { possessão de Dona Sara não } \\
\text { estão ligados à ingestão de } \\
\text { qualquer substância ou de uma } \\
\text { condição médica. }\end{array}$ \\
\hline
\end{tabular}

Fonte: Elaborado pelos autores.

O segundo período tem início aos 27 anos, quando Dona Sara começa a praticar rituais regulares de Umbanda. Ela passa a ter o controle sobre o início das experiências de possessão e tem também uma rede social funcional que acolhe e explica suas experiências incomuns. Há um sentimento de satisfação sobre suas experiências de possessão após a pertença ao grupo de Umbanda. Para além disso, ela agora atua como líder religiosa cujos conselhos morais e espirituais são procurados pela sua comunidade.

Se dividirmos sua vida entre as etapas pré e pós pertença ao grupo de Umbanda podemos analisar que, seguindo a forma como o DSM-5 estrutura seus critérios, na primeira etapa Dona Sara atenderia a todos os cinco critérios de Transtorno Dissociativo de Identidade (ver Tabela 1). Em relação ao critério A, Dona Sara experimenta regularmente uma série de pensamentos intrusivos e estados afetivos diferentes de seu eu cotidiano que culminam na experiência de possessão, cuja fonte é desconhecida (ela descreveu uma perda de consciência e memória, mas não a atribui a uma "entidade"). Em relação ao critério $C$, tais como a 
intolerância social e preconceito, sua angústia é causada por intrusões de pensamentos e emoções recorrentes, alterações do sentido de si mesma/ sentido do eu (por exemplo, sentindo como se seu corpo ou suas ações não fossem dela própria), mudanças ímpares de percepção (por exemplo, sentindo-se separada de seu corpo), e a falta de controle frente a essas experiências incomuns.

Na segunda etapa de sua vida, porém, ela só preenche os critérios A, B e E: experimenta regularmente estados de possessão dentro de sua comunidade religiosa de Umbanda, mas pode controlar o surgimento deste fenômeno, e encontra nessa comunidade apoio social, aceitação e um quadro de sentido existencial e metafísico para suas experiências incomuns.

Há, portanto, uma questão crucial que fica em aberto com o caso de Dona Sara: se ela tivesse sido vista por um médico/psiquiatra durante a primeira fase de suas experiências, seria provável que fosse diagnosticada com Transtorno Dissociativo de Identidade? Sim, é bastante provável mas seria isso um diagnóstico preciso? Podemos interpretar a evolução das experiências de possessão de Dona Sara de duas maneiras. Por um lado, é possível argumentar que, na primeira parte de sua vida, ela sofria de Transtorno Dissociativo de Identidade, mas esta desordem, posteriormente diminuiu quando ela entrou em um grupo religioso, já que este lhe proporcionou apoio social, um quadro espiritual para interpretar suas experiências, bem como a formação necessária para controlar e desenvolver essas experiências. Se considerarmos a ligação positiva com o grupo como espelhando a de um terapeuta individual, isso ajudaria a explicar a remissão dos seus sintomas de Transtorno Dissociativo de Identidade (BAARS ET AL., 2011). Por outro lado, a caracterização consistente dos estados de possessão, por ela própria, como positivos e agradáveis, apesar do sofrimento derivado de sua falta de aceitação social, sugere que um diagnóstico de Transtorno Dissociativo de Identidade na primeira parte de sua vida seria clinicamente inadequado.

Esse segundo argumento parece mais robusto, por várias razões. Ele se encaixa melhor com a teoria de uma predisposição natural para experiências incomuns, como expressão de traços de personalidade, como a esquizotipia, que só em seu extremo estão associados com doença mental (ALMINHANA, 2012; CLARIDGE, 1997). Desde tenra idade, Dona Sara 
mostrou uma disposição para experiências incomuns; se, durante a sua infância e adolescência ela tivesse encontrado uma comunidade de apoio e o quadro existencial para dar sentido a essas experiências, é bastante provável que ela não teria se sentido ameaçada ou angustiada. Isto é o que finalmente aconteceu quando ela entrou no grupo de Umbanda, onde ela floresceu, em parte por causa de sua susceptibilidade natural para experimentar estados de possessão. Um diagnóstico de Transtorno Dissociativo de Identidade na primeira parte da sua vida refletiria uma falta de entendimento das raízes sociais do sofrimento de Dona Sara, e só iria aumentar o seu sofrimento.

\section{Considerações finais}

Por ser o Brasil um país com uma vasta riqueza de práticas religiosas de possessão, este trabalho teve como intenção contribuir para se compreender melhor as características dessas vivências e o que será necessário para melhor saber lidar com elas. Apesar de aparentemente contraditória, a escolha de uma líder religiosa para essa análise - em tese uma pessoa potencialmente saudável do ponto de vista da saúde mental - o seu caso é rico e relevante, já que inclui uma história pessoal do fenômeno que remonta a uma idade bem jovem. Isto nos permitiu analisar como essas experiências incomuns a impactaram, tanto do ponto de vista individual como da sua família, religião e comunidade. Permitiu também traçar a evolução dessa experiência e comparar o período antes e depois da sua inserção no contexto religioso da Umbanda.

A revisão periódica do DSM oferece oportunidades para revisitar os pressupostos subjacentes aos vários diagnósticos, de acordo com novas evidências, de modo a redefinir e refinar os critérios diagnósticos vigentes. O nosso artigo pode contribuir para essa revisão. Para uma futura revisão dos critérios de Transtorno Dissociativo de Identidade, em relação a episódios de possessão, sugerimos uma maior atenção ao contexto social e à potencial não-aceitação desse fenômeno, não obstante a pluralidade cultural e religiosa do Brasil. Note-se aliás, um certo crescimento 
de episódios de intolerância religiosa para com religiões afro-brasileiras de possessão religiões que praticam também um tipo de possessão (pelo Espírito Santo, por exemplo). É importante, nesse contexto, o DSM-5 rever e ampliar suas notas, nomeadamente as que dizem:

O Transtorno Dissociativo de Identidade na forma de possessão pode ser diferenciado de estados de possessão culturalmente aceitos no sentido de que o primeiro é involuntário, angustiante, incontrolável e muitas vezes recorrente ou persistente; envolve conflito entre o indivíduo e seus ambientes familiar, social ou ocupacional; e manifesta-se em momentos e lugares que violam as normas da cultura ou da religião" (APA, p. 295).

Embora os critérios de diagnóstico do DSM-5 $(300,14)$ tenham sido preparados de modo a tentar diferenciar estados saudáveis de possessão de experiências patológicas, ainda é precoce afirmar que ele disponha de informações suficientemente amplas e seguras para um manejo clínico que possa envolver experiências recorrentes de possessão, dentro ou fora de contexto religioso. Um entendimento mais acurado das fronteiras entre possessão saudável e patológica informará não apenas clínicos, mas comunidades religiosas que praticam rituais de possessão. O Brasil tem muito a oferecer nessa área e deverá haver uma maior sensibilização dos psicólogos que estudam religião no nosso país para esta temática — uma temática universal, mas que atravessa o tecido social brasileiro de modo único. Fortalecer a pesquisa nessa área envolve coragem dos acadêmicos brasileiros que porventura se sentem pouco à vontade, perante seus colegas internacionais, em falar de temas tão "arcaicos" ou "primitivos" quanto a possessão, e estarão mais interessados em alinhar por temáticas mais da moda, como por exemplo a mindfulness, de raiz budista. Quem sabe se poderão matar dois pássaros com uma só cajadada? Aumentando a pesquisa sobre a relação desses estados de consciência com a saúde mental, iremos talvez reduzir o estigma e marginalização de que alguns grupos religiosos (sobretudo afro-brasileiros) ainda são alvo e, por outro lado, ajudar a que os psicólogos brasileiros se sintam mais à vontade para apresentar aos seus colegas internacionais o que se passa em sua própria casa. 


\section{Referências}

ALMEIDA, A. M.; ALVARADO, C.; ZANGARI, W. Transtornos Dissociativos (ou Conversivos). Psiquiatra Básica 2. ed, Porto Alegre, Artmed, v. 1, p. 285-297, 2007.

ALMINHANA, L. A personalidade como critério para o diagnóstico diferencial entre experiências anômalas e transtornos mentais. Tese (Doutorado em Saúde Brasileira) - Universidade Federal de Juiz de Fora, Juiz de fora, 2012.

AMERICAN PSYCHIATRIC ASSOCIATION. Diagnostic and Statistical Manual of Mental Health Disorders: DSM 5. 5 ed. Washington D.C. \& London: American Psychiatric Publishing, 2013. 947p.

BASTIDE, R. Les religions africaines au Brésil. Paris : Presses Universitaires de France, 1995.

BAARS, E. W.; et al. Predicting stabilizing treatment outcomes for complex post traumatic stress disorder and dissociative identity disorder: An expertise-based prognostic model. Journal of Trauma \& Dissociation, v. 12, n. 1, p. 67-87, 2011.

BOURGUIGNON, E. Religion, Altered States of Consciousness and Social Change. Columbus: Ohio State University Press, 1973.

CLARIDGE, G. Schizotypy: Implications for Illness and Health. Oxford: Oxford University Press, 1997.

COHEN. E. The mind possessed: The cognition of spirit possession in an AfroBrazilian religious tradition. New York: Oxford University Press, 2007.

GROF, S.; GROF, C. Emergência Espiritual: crise e transformação espiritual. São Paulo: Cultrix, 2001.

Recebido: 03/11/2016

Received: 11/03/2016

Aprovado: 14/04/2017

Approved: 04/14/2017 